\title{
Exploring and Facilitating Learning Management System Adoption
}

\author{
Qian Liu and Susan Geertshuis \\ The University of Auckland Business School \\ Owen G Glenn Building, 12 Grafton Road, Auckland, New Zealand \\ s.geertshuis@auckland.ac.nz
}

\begin{abstract}
The implementation of learning technologies across organisations is rarely uniform despite apparent equity in access to training and support. The research aims to explore the origins of differential adoption in the context of the introduction of a learning management system. Three exploratory studies are described, conducted as parts of a longitudinal insider action research project. The first draws on one of the authors' reflective journal that transcends the introduction, launch, and implementation of a pan-university Learning Management System. The second analyses focus group data, firstly, from technology staff supporting the adoption process and, secondly, from teaching staff who adopted the new system. The third reviews training feedback questionnaires filled out by teaching staff who attended training sessions. By triangulating data from three approaches, we provide insights into the antecedent attitudes and capacities which shape the adoption of learning technologies by academic teaching staff. The implications for supporting learning technology adoption is outlined.
\end{abstract}

\section{KEYWORDS}

Educational technology, Learning technologies, Learning management system, Technology adoption, Higher education

\section{INTRODUCTION}

Learning Management System (LMS) refers to the infrastructure that allows teaching staff to design and deliver instructional content, supervise learning progress, and communicate with learners in the online environment [1-3]. LMSs have been extensively implemented by universities in recent years $[4,5]$, often with the assumption that an LMS will stimulate change in teaching practice to better meet students' learning needs and enhance a university's competitiveness [2, 3]. However, researchers $[4,6,7]$ have argued that an LMS may not achieve its potential in transforming education, as studies have consistently demonstrated that LMSs are used primarily for material distribution rather than as a means of enhancing communication or interaction [8-10]. This may not be too much of a surprise since not only has information systems research documented various resistance behaviours when organisations implement IT innovations [11], but change management research has also indicated that only $30 \%$ of organisational changes will be adopted by employees [12]. Similarly, in the field of educational change and teacher development, the underuse of educational technologies and teachers' resistance to change has been reported $[13,14]$.

The research explores the origins of differential adoption and ways to better facilitate the adoption process in a New Zealand university where a new LMS is implemented. Our research emphasizes the human and contextual aspects of LMS adoption.

The remainder of the paper unfolds in the following way. We first briefly review the literature on innovation diffusion, information systems, and educational technologies. Second, we describe our research approach and context. Then, we present our findings from analyses of reflective journal, focus group and training evaluation. We conclude by discussing our research findings and suggesting directions for 
future research and the implications for supporting learning technology adoption.

\section{LITERATURE REVIEW}

Influenced by Rogers' [15] seminal work on innovation diffusion, researchers view technology adoption as a behavioural change resulting from individuals' decision making [16]. The assumption of adoption as a decision made by the adopter has been accepted in many fields, such as medical and healthcare [17], education [18], and sociology [19]. In addition, innovation diffusion theory primarily deals with diffusion, which describes how innovations spread through a whole population rather than explaining adoption at the individual level [15, 16]. However, this assumption may not explain technology adoption in organisations where employees' adoption is mandated. Employees' technology adoption in organisations may be reflected as a process of learning about and making use of the technology to achieve work tasks [16]. Therefore, adoption research following the tradition of innovation diffusion theory may not provide sufficient understanding of differential adoption among employees in organisational context.

Research in the discipline of information systems has studied the use of computers and information systems [20, 21]. Some of the most significant theories and models, such as Theory of Planned Behaviour [22, 23], Technology Acceptance Model [24, 25], and Unified Technology Acceptance and Use Theory [21] have been applied to various settings. Cognitive factors, such as perceived ease of use[20], usefulness[20], performance expectation[21], efforts expectation[21], and self-efficacy[26], as well as contextual factors, such as social influence[27], behavioural control[28], facilitating conditions and support[27], are identified as predictors of intention to use and actual use of technologies. However, this stream of research views the use in a dichotomous manner: use or non-use. The use of computers or information systems is measured by the number of features used and use frequencies [27, 29, 30]. While this approach provides an assessment of use, it does not enable us to understand how the use came about or the purpose to which it is put.

Researchers have realised that the use of technologies may occur at different levels and a dichotomous view may not represent reality. For instance, Burton-Jones and Straub [31] suggested that, instead of measuring the frequency of use, system use should encompass three elements: the system, the work tasks, and the people. Jasperson and Carter [32] described three types of use behaviours: individual feature adoption decision, individual feature use, and individual feature extension. Saeed and Abdinnour [33] developed this idea and identified three stages of use: routinization stage, infusion stage, and extension stage. However, this research still takes a featurecentric view, which concerns the actual usage of system features, but fails to represent the dynamics of human behaviour in the process of learning to use technologies.

Within educational settings, attempts have been made to understand the use of LMSs. For instance, Cigdem and Topcu [34] combined the Technology Acceptance Model and the Theory of Planned Behaviour to explore the use of an LMS. Janossy [35] proposed a five-level model to capture the richness of LMS use. However, the former only measures the intention to use which is an over-simplification, whereas the latter remains within a feature-centric view that cannot capture the differential behaviour of individuals engaging with technologies.

Research on technology integration and classroom technology has shown some unique findings regarding teachers' use of technologies. First, teachers' beliefs about technology have been suggested in shaping their subsequent use of technologies [36-39]. This is similar to information systems research 
where general computer self-efficacy, and attitude towards computers are predictive of specific software-related self-efficacy and use [40-43]. Second, teachers' beliefs about teaching are identified as having a positive influence on technology use [44-46]. Anderson and Groulx [47] and Petko [48] both found that constructive beliefs were significant antecedents of teachers' technology integration. Information systems researchers [49-51] have suggested that the fit between work practice and information systems predicts system use. Further, teachers' beliefs about teaching, which is reflected in teachers' work practice, may influence their use of technology. Third, teachers' identity and openness to change have also been found to affect use of learning technologies [52-54].

\section{METHOD}

We take an insider action research approach. Action research is viewed as a collaborative, reflexive, and interventionist process concerned with developing practical knowledge $[55,56]$. It is characterised as a participatory and democratic process that seeks solutions to practical problems with the combination of theory and practice, as well as action and reflection [57, 58]. Insider action research refers to situations where members of an organisation seek to inquire into the working of their own organizational system [59], and it has become an important way of understanding and changing organisations [60]. We select this approach because insider action research can generate useful knowledge about how organisations manage change, and how key actors perceive and enact their roles concerning change [61]. We believe that in contexts where change is implemented as a top-down decision, a bottom-up, democratic research approach may provide additional insights that might have been overlooked by the organisation.
The research took place at the Business School of a New Zealand university. A new LMS was implemented university-wide to replace the existing LMS. The idea of introducing a new LMS was to improve students' learning experience and enhance the university's teaching practice. The new LMS is perceived to be excellent at enabling interaction between teachers and students, supporting various forms of learning and teaching, as well as integrating other educational technologies currently used by teaching staff. The decision to replace the current LMS was made in early 2014, and the new LMS was chosen by the university management in early 2015. In June 2015, the university formally announced the decision, and LMS facilitators were recruited two months later from Schools and Faculties within the university. LMS facilitators were provided with initial training in the middle of August 2015 and they were assigned to each Faculty to provide training and support. By the end of March 2016, university staff have used the new LMS for designing and delivering courses. Within the Business School, the Learning and Teaching Team was tasked with supporting the LMS adoption, and around 150 Business School staff attended two-hour foundation sessions, special topic sessions, one-to-one sessions, and were provided with email and 24/7 phone support. The LMS project team consisted of nine technology staff members: a project manager, a learning designer, a media producer, four LMS facilitators, and two undergraduate students who worked part-time to support training and staff inquires, as well as the Director of Learning and Teaching. The first author was employed as one of LMS facilitators by the project team.

We obtained qualitative data through two approaches and three sources. The first source was a reflective journal, which was written in the first person, aimed at developing understanding, and making connections [62]. It emphasizes the importance of learning from practice, which accords with practical-oriented 
action research. Written reflection has always had a place within ethnographic methods [62] and has been considered as a form of qualitative data, especially for action research [63]. However, different from field notes, reflective journals are more subjective as they aim to seek practical solutions through reflexivity [64].

The first author worked as a technology staff member within the Business School, and, as part of his team role, he compiled a reflective journal. Content from the researcher's reflective journal used in this research covers the period from July 2015 to March 2016, encompassing the introduction, launch, and implementation of the LMS. Jasper [62] indicated that analysis of reflective writing can be approached in the same ways as any other narrative data. We used conventional content analysis [65] to analyse the reflective journal, with the assistance of data analysis software Nvivo 11.

We also conducted focus groups from two sources. Focus groups are considered appropriate to elicit participants' attitudes and perceptions [66] and are commonly used for exploratory research [67].

The two focus groups were held after the launch of the first wave of courses. We used the same interview guideline which was based on findings from existing literature, the reflective journal, and issues encountered by technology staff. The project manager sent the invitations to the participants and arranged the focus groups. The second author, the Director of Learning and Teaching, facilitated the focus groups. Discussions in both sessions were recorded and transcribed.

The first focus group was held in early March 2016 with the aim of capturing perceptions from technology staff. Nine technology staff members participated in the focus group. The second focus group was conducted one month later, and the participants comprised seven teaching staff members. Both focus groups were around one hour in duration. Similarly, we used Nvivo 11 to conduct conventional content analysis.

We further analysed qualitative feedback from staff who attended training sessions provided by technology staff in the Business School with the aim of informing practice. We used training feedback as complementary data [68]. Together with reflective journals and focus group data which explores the origins of differential adoption among teaching staff, training feedback was analysed to shade light upon ways that may better facilitate the LMS adoption. A two-hour training was provided to staff during the LMS introduction phase. Training feedback was sought after each training session via online questionnaires and paper copies. The questionnaire asks about overall satisfaction with the training session, improvements that can be made for the training session, and additional resources and support needed after training sessions. In total, there are 107 online and paper copies returned.

\section{RESULTS}

\subsection{Results from Reflective Journal}

Four barriers and enablers were identified through analysis of the journal. They were computer skills, emotions, conceptions of the role of an LMS, and the desire to re-create old work practice in the new environment.

Computer skills were identified repeatedly in the journal as barriers to mastering the LMS functionality. The journal referred to teaching staff's difficulties with simple tasks, such as copy and paste; "when you don't know how to copy and paste through keyboard shortcuts, it is natural to spend 5 minutes to create 1 question (line $185^{1}$ )", saving; "she did not save the edit. It happened a few times so we ended up editing again and again (line556)", finding downloaded files; "some staff did not know

1 Refers to the line number of the text from the reflective journal 
where to find the document downloaded from the old LMS when the facilitator was introducing the new LMS (line298)", filing conventions and collaboration protocols; "the skill set should include work-related skills such as document skills and collaboration skills (line216)", and inability to locate buttons and features; "it was the locating of specific buttons that troubled us (line 225)", that may reflect a lack of familiarity with website and system layouts in general. The lack of computer skills was posited as a distractor, an additional cognitive load, a hindrance; "these basic skills might hinder one's learning in terms of using advanced information systems (line559)" and time wastage. "If it takes 5 minutes to create a single question... I do not think they will have enough time to do it (line189-193)". Reflections include the observation that some teaching staff were unaware that their skills were limited; "they did not realise that they needed to develop their computer skills (line199)" and erroneously attributed their frustration to the LMS. "The lack of computer skills hindered their use of the LMS, but they would not necessarily know. When they found that the new LMS consumed too much of their time, they would complain that the LMS was too demanding and try to avoid using it: 'If I could go offline, I would not make it an online activity' (line201-203)".

Conversely, advanced computer skills, and high levels of engagement with learning technologies seemed to facilitate independence and a willingness to "click around". "For those who are quite tech-savvy, they just need to know what features are available. They cover in their mind 'it can do this' and they have got some idea of how to plan their course (line461464)".

It was apparent from the journal that the process of adopting new technologies could be emotionally charged and anxiety provoking. The journal made a number of references to the emotions of teaching staff. These ranged from a reluctance to change and frustration with the uncertainty; "here was some reluctance. They just wanted to upload files (line399)" to angry outbursts; "The member of staff started to complain how ridiculous and meaningless the feature was (line463)", and panic when the unexpected happened. "He told me that he was in a panic about using the LMS (line 407); a minor problem would cause a huge panic (line540)".

Patience and the willingness to work with individuals on a one-to-one and on-call basis facilitated the process. "He did not understand why he needed to use this feature because he only had two readings for this course. He kept complaining for several minutes. I thought it was not polite to interrupt him to explain the significant purpose. When he was done, I just explained that other staff might need to use this feature as their course had many readings... He then recomposed himself and thanked me for my help. (line 467)".

While a safe and private space to learn about the LMS was valued; "they can ask in a safe place (line 447)", high levels of anxiety created a sense of urgency and a willingness to seek help. "It was an emergency when a member of administration staff forwarded an email in which a student said that he could not submit assignment (line 535)'”. Having time to listen to teachers personal experiences and relate them to the LMS not only eased anxieties, it also served as a motivator. "Although practical solutions and strategies did not come up either, conversations went to personal feelings about technologies, and associations with personal experience were made from time to time. For instance, when introduced to the Discussion feature, trainees commented how amazing technological innovations could be and how easy the LMS was (line 453-456)".

One dominant approach to adopting the new LMS - supported by commentary in the journal notes - was an effort to recreate previous work practices; "trainees in my training session constantly asked questions in terms of their 
work practice (line270)", rather than to embrace new possibilities. "They would, during the training, ask if there was any change in work practice (line358)". Teaching staff appeared to reject new features if they did not fit with existing practices. "She constantly commented the inappropriateness that was brought by the new LMS because it did not fit with the teaching practice here (line 496)". Similarly, if teaching staff could not replicate their old practice, they were reported as being frustrated even though best practice but different solutions existed. "She was extremely unhappy because she thought this added workload to lecturers and administration staff. When I suggested that the university actually encouraged all communication with students being made within the LMS instead of using university email, she remarked that the university did not understand how they taught (line505-510)".

Attempts to replicate past practices were selflimiting, but were also suggested as a potential means of easing the adoption process. The journal recorded events where training approached teaching practice or shifted towards making the relevance of functionality explicit. "You may tell them what this function actually does within the system...but this is not enough. Trainees will come to you, asking what it means to their teaching practice... (line274-276); Training should also incorporate work process knowledge (line361); I was trying to tell them the consequences of the feature and used some practical examples. This strategy seemed to work very well (line348-350)".

The journal noted differences between teaching staff in conceptions of the role of the LMS and its centrality to their role as teachers. Some members of staff appeared to regard the LMS as merely a repository; "they just wanted to upload files (line400)", some were reluctant to provide instruction to students; "I think she generally does not like to get involved too much with students (line 504)", others regarded the communication functions as unnecessary; "she maintained that there was no need to provide additional communication channels within the LMS which will only add workload (line509)", others, while responding to student pressure to use features, did so in a minimalistic way. "She did not want to know any additional features that the LMS Quiz brought (line522)".

The analysis of the journal provide lived examples over an extended period, but they are derived from the experiences of one action researcher. The focus groups which are described below provide an opportunity to identify supporting or alternative ways of understanding the adoption process from a range of perspectives.

\subsection{Results from Focus Groups}

Our analysis of data from focus groups revealed four themes related to the LMS adoption. They were conceptions of teacher role and teaching, attitude towards technology and previous experience with LMSs, change-related attitudes, and training and support.

First, members of focus groups repeatedly referred to teachers' conception of their role and teaching. Technology staff reported that teaching staff approached their role as a teacher, either from the teacher-centred or learner-centred perspective; "I think that split falls along that line of teacher and learnercentric lines (line 259, $F 1^{2}$ )", and the teachercentred view was perceived as merely transmitting knowledge in front of the class. "Teaching is the process of standing up and delivering knowledge orally (line 245, F1); 'my role as a lecturer is that I show up in front of classes' (line 225, F1)'. Therefore, for those with the teacher-centred view, additional tasks, such as using learning technologies, were viewed as disturbing and unnecessary; " "all the

\footnotetext{
${ }^{2}$ The number refers to the line number in the transcript, F1 refers to the focus group with technology staff. F2 refers to the focus group with teaching staff.
} 
other stuff is extra annoying things that management is asking me to do, it is not really teaching' (line 246, F1); 'I've got my stuff prepared and I teach them in class', anything else is probably not something they consider too much (line 227, F1)", which led to a reluctance to adopt the LMS. "I was talking to a teacher during one of the training sessions...we came to the Syllabus page and all she did was just copy the course outline...my suggestion was at least you say something about the course. She said 'no, there is no need for that'. I could not resist the urge to say 'but this sounds like doing this to students (dropping page on the desk)'. She said 'so what?' that was her reaction (line 209-211, F1)". Similarly, teaching staff also commented that those who viewed teaching as delivering and disseminating knowledge would not feel comfortable to interact with students online. "For some people, if a student asks a question then you just answer it, but for others, it's too uncomfortable (line 528, F2); Communicating with students online is not natural... I am used to 'I'm the lecturer. I stand there and deliver', yet there is a function in the LMS where students can reply to my announcement (line 521-523, F2)".

In addition, both technology and teaching staff mentioned that the priority of teaching, or the importance of teaching was conceived differently and those who were not committed to teaching showed a lack of interest in adopting the LMS; "I think they just can't be bothered. Teaching is not that important (line $503,505, F 2)$ ", whereas those who had teaching as their priority were likely to "push the boundary". "What I have found is that those who are very keen and who have teaching in their higher priority over their other commitments will be the ones who keep pushing the boundary (line 328-330, F1)".

Second, data from focus groups revealed that attitude towards technology and previous experience with LMSs were associated with the adoption of the new LMS. Both technology and teaching staff configured that those who were generally positive to technologies would be more willing to adopt the LMS. "If you have got those guys who are in favour of using technologies for teaching purposes, they will be positive to learn this new system (line 47, F1); some people are not comfortable with the technology (line 519, F2)". By contrast, the relationship between previous experience with LMSs and the adoption of the new LMS was complex. Those who did not use the old LMS were unlikely to use the new LMS. "They don't use the old LMS much and so they don't, they told me that, know what the use of implementing the new LMS is (line 47, F1); 'When we had the old LMS, some people wouldn't use it' 'Was it always the same folks?' 'Pretty much' (line 484-486, F2)'. Those who used the old LMS would rather replicate what they did in the past on the new LMS, than embrace new potentials. "If they had used the old LMS before, they wanted to achieve the same thing they did in the old LMS (line 108, F1); we are just doing the same thing as in the old LMS (line 297, F2)".

Third, technology staff and teaching staff both referred to the role of change-related attitudes in the LMS adoption process. Teaching staff who were more open to change would likely pick up the LMS and try things out; "I think if they are quite comfortable with picking up new things, then they are quite happy to just click around and try different things (line 82, F1)', whereas those who viewed change negatively were afraid to adopt the LMS simply because the LMS was a change. "It's this fear factor. It's just something new (line 337, F2); the staff member who was involved with the design was quite adamant to stick to how things were (line 280, F1); it was that fear of change, so it wasn't what it was, but that it was a change (line 286, F1)'”. However, teaching staff further elaborated that their change-related attitudes were probably driven by the desire to maintain a good image in front of students. "I've been changing things around quite a lot and I 
actually don't care if students think I'm stupid or not...but some people are saying that 'if I change things, I will look like that I don't know what I'm doing' (line 573-540, F2). Because in our department, we don't want to look like we don't know how to use it! They are very, very unforgiving when the $X$ [discipline] lecturer can't use the $X$ tool...they might forgive someone else...they don't forgive us... (line 552-554, F2)".

Fourth, we identified from two focus groups that training and support were enablers of the LMS adoption. Teaching staff repeatedly indicated that the whole implementation of the LMS had been very successful and the support provided by the Business School had been very good. "If you think what the University has done and what the Business School has done, we've just replaced a whole LMS and I think it has gone fantastically well and I think the support has been outstanding (line 89-91, F2)'”. Particularly, one-to-one sessions were the most popular; "staff were much more willing to come to a one-to-one session than they were to come to any other type of training (line 445, F1)", while the two-hour foundation sessions were perceived as overwhelming. "The two-hour workshops were quite comprehensive and quite overwhelming (line 27, F2)". Technology staff explained that one-to-one sessions provided opportunities for teaching staff to ask specific questions related to their own courses; "they've got specific questions for that specific course and they are more interactive (line 380, F1)', and probably more importantly, it provided a comfortable and safe atmosphere that allowed teaching staff to experiment with the LMS without damaging their image. "They would like somebody to sit there so that they feel 'I'm not going to muck it up. I'm going to do this right, because somebody is sitting with me' (line 48, F1). They are not afraid that everyone is around them or that they are asking stupid little questions...they are more open to their questions and they are more willing to learn as we sit there next to them (line 381-383, F1)".
However, technology staff argued that without two-hour foundation sessions, the effect of oneto-one sessions may have been restricted. "It's difficult when they haven't been to the two-hour training session...because they don't know the foundations (line 394, F1); It [the two-hour session] is still useful as a primer. It prepares you and you can learn better once you are in the one-to-one session (line 386, F1)".

When asked if there were any improvements in teaching with the implementation of the LMS, both technology and teaching staff indicated that there was little improvement in teaching practice now; "I don't think the LMS will cause [pedagogical] lifts (line 697, F1); it hasn't changed at least the way we are teaching our courses (line 297, F2)", yet they agreed that the adoption process for most teaching staff was incremental. "'Let me do what I had...then we'll push another step forward and try something else (line 150, F1). They are getting their heads around, and they are not trying to do all singing and dancing at the moment (line 286, F2)". As for future training and support, learning from other colleagues seemed to be a commonly preferred strategy. Teaching staff recommended to have some kind of feedback on functionality people were using on the LMS; "here is the population of academics in the Business School and so many percent are doing this. That might help motivate people (line 652, F2)", while technology staff suggested organising sharing events to encourage the LMS adoption. "Usually there are one or two really bright stars per faculty. If we had it faculty wide it would allow the bright stars to shine brightly over all the departments (line 521, F1)". Technology staff furthered the idea with recommendations to capture the demand from students for having different features. "Perhaps one of those things is to audit and look at the stuff that students most want as we move forward, and make sure that we have got most courses hitting that for most of the time (line 766-769, F1)". However, technology and teaching staff diverged in their thinking about 
future support. Teaching staff predominantly requested support on specific features which did not fit very well with their teaching practice. "We are going to need quite a bit of support around grading time (line 28, F2); we don't know anything about it in terms of entering marks on the system and doing scaling (line 40, F2); just for the entering of the marks, because we have 'plussage' in our department... (line 61, F2)'”. By contrast, technology staff focused on support that might shift current teaching practice. "We need to get students to say how they feel about the new LMS...then lecturers will be able to read those feedbacks and then they'll probably think about how to improve their course (line 689, F1)"”.

\subsection{Results from training feedback}

Five themes emerged from our analysis of training feedback. First, we found that cohorts of teaching staff displayed varying adoption pattern which implied that implementation guided by the 'one fits all' approach may not fully facilitate the LMS adoption across individual teaching staff member. Second, teaching staff, although displaying varying adoption patterns are active learners who prefer the hands-on experience and learn well by experimenting and using the LMS directly. Third, professional practice serves as the start point of adoption and relating the LMS to existing practice enhances teachers' sensemaking process. Fourth, providing one-to-one support after the training session to assist teaching staff to build real courses may best address their concerns with the LMS adoption (picture). Lastly, sharing of 'best practice' or 'template' that goes beyond the introduction of the LMS functionalities may provide directions and set expectations for teaching staff, thus bringing along the LMS adoption.

Training feedback echoed the reflective journal and focus group transcripts: teaching staff displayed differential adoption patterns. Some teaching staff suggested to "group people who require the same type of training together (line 21)" as teachers may hold different responsibilities and use the LMS functionalities in different ways. Providing only a standard training session may not fully address individual needs. Some found the session "was well structured and covered the important points (line 70) and was not overwhelming (line 124)" and "the pace was appropriate (line 31)". Others found it "covered too much for the first introductory session (line 86)" and needed to "slow down at some point (line 82)". Technology staff facilitating training sessions were therefore challenged to "make sure everyone was on the same page before moving forward (line 59)". Particularly, computer skills seemed to shape the adoption pattern: "perhaps knowing the computer skills of the participants prior to the training will be helpful, which makes the session more effective for different levels of users (line 498)". In addition, teaching staff also requested various materials to help them use the LMS after attending the training. Some asked for a "step-by-step operation guidelines (line 286)"; some thought it would be enough to have a more general "list of resources that the University or Business School recommends their staff to use (line 208)"; some were afraid of making mistakes and requested for "a checklist of what to avoid when setting up a course, a Don't Do list (line 116)"; others would prefer to have "a list of troubleshooting questions (line 250)" to solve problems themselves.

Our analysis reveals that teaching staff are active learners who value the hands-on experience and prefer to take the lead in the learning process and explore the LMS themselves in simulated or real courses. Teaching staff valued hands-on practice and preferred to have "more hands-on tasks to do in sessions (line 65)" and "more time to play to enter information (line 66)". Particularly, a dummy course in a simulated environment allowing self-exploration of the LMS 
functionalities was favored. They suggested to "include a dummy course (line 68)", which allows them "to manipulate (line 89)" and "transfer a course outline, assignment, tests, etc. to the LMS during sessions to stimulate actually setting up a course (line 51)". The strength of a dummy course that "has all the items, students, lists, and assignments (line 160)" is that it helped teaching staff to "learn more functions with a more realistic view (line 162)". Several comments even suggested that time should be given to teaching staff "to work on (their) own managed course (line 174) or specific course (line 299)" during the training session. As LMSs bring teacher and students together in an online platform that enables communication and even co-creation, teaching staff underscore the importance of having students in the dummy course in order to fully understand the way the LMS works. Teaching staff would like to "see a full dummy course with student works... so (they) could see all the student analytics (line 49)". Otherwise, "there are many functionalities (they) cannot play with (line 157)".

Previous professional practice seems to work as the starting point for teaching staff to make sense of the new LMS. As there was some disparity and inconsistency between the old LMS and the new LMS, teaching staff repeatedly referred to the old LMS when learning about the new LMS. A list of "term translation (line 90)", or a "summary (line 288)" on how similar functions are called in both LMSs seemed to activate sense-making. A detailed "comparison with the old LMS (line 148)" and a "more advanced list of features that are no longer available on the new LMS (line 268)" were preferred because "(they) related to what (the teaching staff) know in the old LMS and where the technology actually works (line 118)."

Consistent with reflective journals and focus group data, one-to-one support seems to be the most favored and desired. Teaching staff indicated that they "benefited from having individual assistance (line 8)" and further suggested that "most staff would need one-toone support (line 195)". One-to-one support offered the availability for teaching staff to "ask for help with specific issues (line 305)" if they "got stuck while actually doing a course upload in the new LMS (line 202)". One-to-one support was also perceived as time-saving and more efficient: "(I) will appreciate a one-to-one assistance to understand how I can easily transfer a well-organized package of course materials from my PC to the new LMS without spending a lot of time going through its idiosyncrasies (line 468)".

Some teaching staff made several references to the importance of sharing standard course templates and 'best practice' and re-thinking pedagogical implications. A recommended course template would help to set up expectations: "(I could use) some model examples of well-designed course with sophisticated features as benchmarks (line 216); I would like to see how other courses use the LMS to build student friendly environment (line 249)". Some suggested to "re-think how courses work, (because) one thing I (the lecturer) personally want to avoid is simply to use the new LMS like the old one. It's a great opportunity to overhaul and improve my course (line 453)". One staff member even suggested that "(learning) design tips would be handy. This session covers the basic mechanics but maybe (include) just two or three things that make the basic design attractive and student friendly (line 245)".

\section{DISCUSSION}

Themes emerged from analyses of the reflective journal, focus group transcripts, and training feedback seemed to converge to four aspects relating to the LMS adoption process.

Results from focus groups demonstrated that the conception of the teacher role and teaching 
shaped the extent to which teaching staff adopted the LMS. Teaching staff with the teacher-centred view regarded teaching as "topup" knowledge to students in class. Therefore, additional tasks were disturbances to teaching, which led to the idea that the role of an LMS was a repository, and communication online with students was uncomfortable. Conversely, learner-centred teaching staff, understood teaching as more than just transmitting knowledge, and therefore, regarded communication with students online as part of the teaching process instead of a burden. This was consistent with Ertmer's [46] suggestion that the second order change, teachers' beliefs about teaching, affects technology use. Our findings confirmed previous empirical research where learner-centred beliefs were positively associated with technology integration $[47,48]$.

Research on information systems and educational technologies indicates that computer self-efficacy and skills [69-71], experience with computers [72, 73], and general attitude towards technology [39, 74, 75] are predictive of computer or technology use. Our research further developed the idea by showing the complex influence of computerrelated attitudes, skills and self-efficacy on LMS adoption. Our data seemed to support that a positive attitude towards computers and technologies in general encouraged the LMS adoption. In addition, levels of computer skills may lead to different adoption pace in practice. Nevertheless, the lack of basic computer skills were associated with excessive cognitive load. Our data also revealed that previous experience with LMSs restricted the extent of initial adoption, because most teaching staff took an incremental approach to adoption. This meant that the initial motivation was just to replicate what they did in the past.

Our data supported Vannatta and Nancy's [54] suggestion that teachers' openness to change affects technology use. Those who were more open to change tended to pick up and experiment with the LMS, while others who did not like change showed a tendency to reject the LMS. The negative attitude towards change was associated with emotional cost ranging from reluctance, anxiety, to panic. In particular, our research further revealed a potential source of negative attitude towards change. Teaching staff reported that the reluctance to change might come from one's fear of damaging his/her image, especially in front of students.

Although the implementation of the LMS has been perceived by teaching staff as 'fantastically well' and training and support provided by the Business School has been 'outstanding', there seemed to be major differences between technology and teaching staff in their understanding of promoting the LMS adoption. Results from reflective journal and the focus group with technology staff, revealed technology staff felt, with the implementation of the LMS, teaching staff should improve their teaching practice. This led to the suggestion that future training and support should focus on shifting and enhancing teaching practice. Conversely, results from the focus group with teaching staff indicated that teaching staff assumed that current teaching practice should be maintained. Wherever the LMS did not fit with current teaching practice, efforts should be made to either change the way the LMS worked or come up with strategies to maintain the old practices within the new LMS. This led to the suggestion that future training and support should predominantly focus on dealing with specific LMS features such as grading. However, training feedback seems to suggest that the division between teaching and technology staff is not irreconcilable. Pedagogical implication was cherished by some teaching staff members.

As an insider action research, findings above informed our practice in two ways. First, our future learning and development interventions need to balance two pairs of competing forces. The first pair concerns the content of training and support. To address teaching staff's expressed needs, the content should cover 
system features. For instance, how traditional grading practice can be achieved within the new LMS needs to be addressed. However, to improve teaching practice, the introduction of educational technologies is not efficient. Efforts should be made to address fundamental issues such as beliefs about teaching [45]. The second pair concerns types of learning strategies. Personalised one-to-one support has been very popular and effective but encouraging share and communication is an important means for personal and professional development [76]. In a study of learning to use technology, Kay [77] concluded that among collaboration, authentic tasks, formal instruction and exploratory learning, collaboration and authentic tasks were the most preferred strategies but collaborative learning was the best predictor of gains in computer knowledge. Given that one-to-one support provided by technology staff is quite similar to learning through authentic tasks, how to design a collaborative learning strategy that stimulates sharing would be an action plan. Second, we propose that strategies beyond learning and development interventions might be equally important in terms of encouraging the LMS adoption. For instance, with the takeup of the new LMS, the university could have made it explicit if changes in teaching practice are needed or encouraged, because the reflective journal and focus group data revealed that teaching staff concerned about how teaching practice could be maintained in the new LMS.

\section{CONCLUSION}

Universities implement organisational wide information systems such as LMSs with the intention to promote teaching practice. The underlying assumption is that staff will comply with the university's decision and adopt new systems. Our research revealed that even in mandatory settings, where one had to adopt a system, the process and extent of adoption differentiated among individuals. Therefore, a new LMS may not necessarily lead to pedagogical uplifts. Our findings indicate that teaching staff's attitude and capabilities shaped by their previous experience and university practice will influence how they learn about, approach, make use of, and support the new LMS. Learning and development interventions that focus only on the general introduction of the new system may not be sufficient to either support adoption or improve teaching practice. Future research should explore ways to influence antecedent attitudes and capabilities in order to enhance higher levels of LMS adoption.

\section{REFERENCES}

[1] W.R. Watson and S.L. Watson, What are learning management systems, what are they not, and what should they become? TechTrends, 2007. 51(2): p. 29.

[2] S. Lonn and S.D. Teasley, Saving time or innovating practice: Investigating perceptions and uses of Learning Management Systems. Computers \& Education, 2009. 53(3): p. 686-694.

[3] H. Coates, R. James, and G. Baldwin, A critical examination of the effects of learning management systems on university teaching and learning. Tertiary education and management, 2005. 11: p. 19-36.

[4] J.E. Klobas and T.J. McGill, The role of involvement in learning management system success. Journal of Computing in Higher Education, 2010. 22(2): p. 114-134.

[5] T. Browne, M. Jenkins, and R. Walker, A longitudinal perspective regarding the use of VLEs by higher education institutions in the United Kingdom. Interactive Learning Environments, 2006. 14(2): p. 177-192.

[6] N. Sclater, Web 2.0, personal learning environments, and the future of learning management systems. Research Bulletin, 2008. 13(13): p. 1-13.

[7] K.E. Rudestam and J. Schoenholtz-Read, The coming of age of adult online education. Handbook of online learning: Innovations in higher education and corporate training, 2002: p. 3-28.

[8] TechnologyResourcesCenter, University of Central Oklahoma Survey on Learning Management Systems. 2011, University of Central Oklahoma: U.S.A. p. 1-7. 
[9] H. Gastfriend, USG Learning Management System Taskforce. 2011, University of Georgia: U.S.A. p. 121.

[10] R. Becker and L. Jokivirta, Online learning in universities: selected data from the 2006 observatory survey. London: Observatory on Borderless Higher Education, 2007.

[11] L. Lapointe and S. Rivard, A Multilevel Model of Resistance to Information Technology Implementation. MIS Quarterly, 2005. 29(3): p. 461491.

[12] T.G. Kim, S. Hornung, and D.M. Rousseau, Changesupportive employee behavior: Antecedents and the moderating role of time. Journal of Management, 2011. 37(6): p. 1664-1693.

[13] L. Deaker, S.J. Stein, and D. Spiller, You can't teach me: exploring academic resistance to teaching development. International Journal for Academic Development, 2016: p. 1-13.

[14] L. Quinn, Understanding resistance: an analysis of discourses in academic staff development. Studies in Higher Education, 2012. 37(1): p. 69-83.

[15] E.M. Rogers, Diffusion of innovations. New York, 1995: p. 12.

[16] E.T. Straub, Understanding technology adoption: Theory and future directions for informal learning. Review of educational research, 2009. 79(2): p. 625649.

[17] T.R. Kratochwill, Theories of Change and Adoption of Innovations: The Evolving Evidence-Based Intervention and Practice Movement in School Psychology. Psychology in the Schools, 2005.

[18] G.E. Hall, Technology's Achilles heel: Achieving high-quality implementation. Journal of Research on Technology in Education, 2010. 42(3): p. 231-253.

[19] G. Deffuant, S. Huet, and F. Amblard, An Individual-Based Model of Innovation Diffusion Mixing Social Value and Individual Benefit. American Journal of Sociology, 2005. 110(4): p. 1041-1069.

[20] F.D. Davis, Perceived usefulness, perceived ease of use, and user acceptance of information technology. MIS quarterly, 1989: p. 319-340.

[21] V. Venkatesh, M. Morris, G.B. Davis, and F.D. Davis, User acceptance of information technology: Toward a unified view. MIS quarterly, 2003: p. 425478.

[22] K. Mathieson, Predicting user intentions: comparing the technology acceptance model with the theory of planned behavior. Information systems research, 1991. 2(3): p. 173-191.
[23] S.S. Kim, The Integrative Framework of Technology Use: an Extension and Test. MIS Quarterly, 2009. 33(3): p. 513-537.

[24] F.D. Davis, R.P. Bagozzi, and P.R. Warshaw, User acceptance of computer technology: a comparison of two theoretical models. Management science, 1989. 35(8): p. 982-1003.

[25] N. Marangunić and A. Granić, Technology acceptance model: a literature review from 1986 to 2013. Universal Access in the Information Society, 2015. 14(1): p. 81-95.

[26] D. Compeau, C.A. Higgins, and S. Huff, Social cognitive theory and individual reactions to computing technology: A longitudinal study. MIS quarterly, 1999: p. 145-158.

[27] R.L. Thompson, C.A. Higgins, and J.M. Howell Personal computing: toward a conceptual model of utilization. MIS quarterly, 1991: p. 125-143.

[28] V. Venkatesh, Determinants of perceived ease of use: Integrating perceived behavioral control, computer anxiety and enjoyment into the technology acceptance model. Information Systems Research, 2000. 11(4): p. 342-365

[29] M. Igbaria, N. Zinatelli, P. Cragg, and A.L. Cavaye, Personal computing acceptance factors in small firms: a structural equation model. MIS quarterly, 1997: p. 279-305.

[30] D. Straub, M. Limayem, and E. Karahanna-Evaristo, Measuring system usage: Implications for IS theory testing. Management science, 1995. 41(8): p. 13281342 .

[31] A. Burton-Jones, and D.W. Straub Jr, Reconceptualizing system usage: An approach and empirical test. Information systems research, 2006. 17(3): p. $228-246$.

[32] J.S. Jasperson, P.E. Carter, and R.W. Zmud, A comprehensive conceptualization of post-adoptive behaviors associated with information technology enabled work systems. Mis Quarterly, 2005. 29(3): p. 525-557.

[33] K.A. Saeed, and S. Abdinnour, Understanding postadoption IS usage stages: an empirical assessment of self-service information systems. Information Systems Journal, 2013. 23(3): p. 219-244.

[34] H. Cigdem, and A. Topcu, Predictors of instructors' behavioral intention to use learning management system: A Turkish vocational college example. Computers in Human Behavior, 2015. 52: p. 22-28.

[35] J. Janossy, Proposed model for evaluating C/LMS faculty usage in higher education institutions. in MBAA conference, Chicago, IL. Retrieved November. 2008. Citeseer. 
[36] J.R. Banas, Teachers' attitudes toward technology: Considerations for designing preservice and practicing teacher instruction. Community \& Junior College Libraries, 2010. 16(2): p. 114-127.

[37] S. Prestridge, The beliefs behind the teacher that influences their ICT practices. Computers \& Education, 2012. 58(1): p. 449-458.

[38] B. Rienties, N. Brouwer, and S. Lygo-Baker, The effects of online professional development on higher education teachers' beliefs and intentions towards learning facilitation and technology. Teaching and Teacher Education, 2013. 29: p. 122-131.

[39] A.T. Ottenbreit-Leftwich, K.D. Glazewski, T.J. Newby, and P.A. Ertmer, Teacher value beliefs associated with using technology: Addressing professional and student needs. Computers \& Education, 2010. 55(3): p. 1321-1335.

[40] G.M. Marakas, M.Y. Yi, and R.D. Johnson, The multilevel and multifaceted character of computer self-efficacy: Toward clarification of the construct and an integrative framework for research. Information systems research, 1998. 9(2): p. 126163.

[41] R. Agarwal, V. Sambamurthy, and R.M. Stair, Research report: the evolving relationship between general and specific computer self-efficacy-an empirical assessment. Information systems research, 2000. 11(4): p. 418-430.

[42] J. Downey, Measuring general computer selfefficacy: The surprising comparison of three instruments in predicting performance, attitudes, and usage. in System Sciences, 2006. HICSS'06. Proceedings of the 39th Annual Hawaii International Conference on. 2006. IEEE.

[43] B. Hasan, Delineating the effects of general and system-specific computer self-efficacy beliefs on IS acceptance. Information \& Management, 2006. 43(5): p. 565-571.

[44] H.J. Becker, Findings from the teaching, learning, and computing survey. education policy analysis archives, 2000. 14: p. 51.

[45] P.A. Ertmer, and A.T. Ottenbreit-Leftwich, Teacher technology change: How knowledge, confidence, beliefs, and culture intersect. Journal of research on Technology in Education, 2010. 42(3): p. 255-284.

[46] P.A. Ertmer, Teacher pedagogical beliefs: The final frontier in our quest for technology integration? Educational technology research and development, 2005. 53(4): p. 25-39.

[47] S.E. Anderson, J.G. Groulx, and R.M. Maninger, Relationships among Preservice Teachers Technology-Related Abilities, Beliefs, and Intentions to Use Technology in Their Future
Classrooms. Journal of Educational Computing Research, 2011. 45(3): p. 321-338.

[48] D. Petko, Teachers' pedagogical beliefs and their use of digital media in classrooms: Sharpening the focus of the 'will, skill, tool'model and integrating teachers' constructivist orientations. Computers \& Education, 2012. 58(4): p. 1351-1359.

[49] D.L. Goodhue and R.L. Thompson, Task-technology fit and individual performance. MIS quarterly, 1995: p. 213-236.

[50] H.-P. Lu and Y.-W. Yang, Toward an understanding of the behavioral intention to use a social networking site: An extension of task-technology fit to socialtechnology fit. Computers in Human Behavior, 2014. 34: p. 323-332.

[51] T.J. McGill and J.E. Klobas, A task-technology fit view of learning management system impact. Computers \& Education, 2009. 52(2): p. 496-508.

[52] S., Mumtaz, Factors affecting teachers' use of information and communications technology: a review of the literature. Journal of information technology for teacher education, 2000. 9(3): p. 319342.

[53] R. Aldunate and M. Nussbaum, Teacher adoption of technology. Computers in Human Behavior, 2013. 29(3): p. 519-524.

[54] R.A. Vannatta and F. Nancy, Teacher dispositions as predictors of classroom technology use. Journal of Research on Technology in Education, 2004. 36(3): p. 253-271.

[55] P. Reason and H. Bradbury, Handbook of action research: Participative inquiry and practice. 2001: Sage.

[56] R. MacIntosh, M. Bonnet, and D. Coghlan, Insider action research: opportunities and challenges. Management Research News, 2007. 30(5): p. 335343.

[57] C. Eden and C. Huxham, Action research for management research. British Journal of Management, 1996. 7(1): p. 75-86.

[58] M. Brydon-Miller, D. Greenwood, and P. Maguire, Why action research? Action research, 2003. 1(1): p. 9-28.

[59] D. Coghlan and T. Brannick, Doing action research in your own organization. 2014: Sage.

[60] D. Coghlan and R. Holian, Editorial: insider action research. Action Research, 2007. 5(1): p. 5-10.

[61] D. Coghlan, Practitioner research for organizational knowledge mechanistic-and organistic-oriented 
approaches to insider action research. Management Learning, 2003. 34(4): p. 451-463.

[62] M.A. Jasper, Using reflective writing within research. Journal of research in nursing, 2005. 10(3): p. $247-260$.

[63] E.A. James, M.T. Milenkiewicz, and A. Bucknam, Participatory action research for educational leadership: Using data-driven decision making to improve schools. 2007: Sage Publications.

[64] R.G. Burgess, Keeping a research diary. Cambridge Journal of Education, 1981. 11(1): p. 75-83.

[65] H.-F. Hsieh and S.E. Shannon, Three approaches to qualitative content analysis. Qualitative health research, 2005. 15(9): p. 1277-1288.

[66] C. Puchta and J. Potter, Focus group practice. 2004: Sage.

[67] J. Stewart and M. O'Donnell, Implementing change in a public agency: Leadership, learning and organisational resilience. International Journal of Public Sector Management, 2007. 20(3): p. 239-251.

[68] M.L. Small, How to conduct a mixed methods study: Recent trends in a rapidly growing literature. Sociology, 2011.37(1), p.57-86.

[69] D. Compeau and C.A. Higgins, Application of social cognitive theory to training for computer skills. Information systems research, 1995. 6(2): p. 118143.

[70] J.E. Scott and S. Walczak, Cognitive engagement with a multimedia ERP training tool: Assessing computer self-efficacy and technology acceptance. Information \& Management, 2009. 46(4): p. 221232.

[71] G. Marakas, R. Johnson, and P.F. Clay, The Evolving Nature of the Computer Self-Efficacy Construct: An Empirical Investigation of Measurement Construction, Validity, Reliability and Stability Over Time. Journal of the Association for Information Systems, 2007. 8(1): p. 2.

[72] S. Taylor and P.A. Todd, Assessing IT usage: The role of prior experience. MIS quarterly, 1995: p. $561-570$.

[73] R.L. Thompson, C.A. Higgins, and J.M. Howell, Influence of experience on personal computer utilization: testing a conceptual model. Journal of Management Information Systems, 1994: p. 167187.

[74] S.-H. Liu, Factors related to pedagogical beliefs of teachers and technology integration. Computers \& Education, 2011. 56(4): p. 1012-1022.
[75] C. Kim, M.K. Kim, C. Lee, J.M. Spetor, and K. DeMeester, Teacher beliefs and technology integration. Teaching and Teacher Education, 2013. 29: p. 76-85.

[76] E. Wenger, Communities of practice and social learning systems. Organization, 2000. 7(2): p. 225246.

[77] R. Kay, A formative analysis of how preservice teachers learn to use technology. Journal of Computer Assisted Learning, 2007. 23(5): p. 366383. 